\title{
Geoquímica e geocronologia em campos de murunduns no Chapadão do Diamante -Serra da Canastra-MG
}

\author{
Geochemistry and geochronology in murundun fields in the diamante square - Serra da \\ Canastra-MG
}

\author{
Fabiana Cristina dos Santos \\ Doutoranda em Geografia pela \\ Universidade Federal de Uberlândia \\ fabianaqgufu@gmail.com \\ Jefferson Gomes Confessor \\ Doutorando em Geografia pela \\ Universidade Federal de Uberlândia \\ djerfsgeo@hotmail.com
}

\begin{abstract}
Resumo
A distribuição dos materiais superficiais nas vertentes em ambiente de Cerrado dispõe de particularidades intrínsecas, que estão relacionadas com o posicionamento topográfico, formato das vertentes, fitofisionomia e com escoamento superficial e subsuperficial da água. Estes aspectos estão associados com a sazonalidade climática, típica deste ambiente. A área de estudo está localizada no Chapadão Diamante do Parque Nacional da Serra da Canastra-MG, onde estão presentes campos de murunduns. A metodologia consistiu em análises de Textura, Luminescência Oticamente Estimulada (LOE) e Difratometria por Raio-X da fração argila. A avaliação prognóstica correlacionou os resultados de forma subjetiva, por se tratar de um estudo embasado em probabilidades, considerando o conhecimento disponível sobre cada atributo na literatura especializada. A análise da área oferece informações importantes, dotada de grande valor geográfico, seja no âmbito da geomorfologia, quanto aos estudos do meio físico integrados aos setores de planejamento e gestão ambiental.
\end{abstract}

Palavras-chave: Geoquímica; Geomorfologia; Datação absoluta.

\begin{abstract}
The distribution of surface materials in the Cerrado slopes has intrinsic characteristics which are related to the topographic positioning, slope format, phytophysiognomy and surface and subsurface runoff. These aspects are associated with the climatic seasonality typical of this environment. The study area is located in Chapadão Diamante at Serra da Canastra National Park-MG where murunduns fields are present. The methodology consisted of texture analysis, Optically Stimulated Luminescence (LOE) and Clay X-ray Diffractometry. The prognostic evaluation correlated the results subjectively because it is a study based on probabilities, considering the available knowledge about each attribute in the specialised literature. The analysis of the area offers important information with great geographical value, whether in the field of geomorphology or studies of the physical environment integrated with the environmental planning and management sectors.
\end{abstract}

Keywords: Geochemistry; Geomorphology; Absolute Dating. 


\section{INTRODUÇÃO}

O território brasileiro dispõe de sete biomas estabelecidos, os quais apresentam associados a eles fitofisionomias distintas, com características e propriedades próprias. Tais fitofisionomias evidenciam, normalmente, funções ecológicas de grande importância para a sustentabilidade desses biomas.

Para alguns autores (ARAÚJO NETO et al., 1986; OLIVEIRA FILHO; FURLEY, 1990; RESENDE et al., 2014), o termo campos de murunduns, engloba uma fitofisionomia caracterizada pela formação de montículos de solo e têm como propriedade o alagamento no período chuvoso de seu entorno. Assim, nos campos de murunduns, o comportamento da água no solo é peculiar, podendo ocorrer elevação do nível do lençol freático, supersaturação e afloramento da água na superfície do solo, logo nas primeiras precipitações advindas do período chuvoso. Durante o período de entre chuvas, o processo se inverte e o esvaziamento e rebaixamento da área úmida no perfil do solo acontece gradualmente ao longo do tempo, conferindo aos campos de murunduns a condição de reservatórios naturais (OLIVEIRA FILHO; FURLEY, 1990; CASTRO JÚNIOR, 2002; RIBEIRO et al., 2008).

Ainda de acordo com a abordagem acima, esses microrrelevos são distribuídos pelo bioma Cerrado, ocorrendo em campos aluviais inundáveis das planícies e depressões, e também em campos brejosos de encosta de planaltos e serras (PAULINO et al., 2015), como observado neste estudo.

A interpretação geomorfológica do relevo é primordial para a compreensão da sequência de eventos que atribuíram a ele determinadas características. Assim, o uso da técnica de datação absoluta, corrobora para a revisão de pesquisas sobre a dinâmica geomorfológica e geocronologia dos processos. Os procedimentos da atualidade para datação de materiais superficiais, viabilizam atribuir períodos específicos da evolução do relevo e a origem de determinadas condições conhecidas ou modeladas (SAMPAIO, 2013).

Com o avanço tecnológico mais acelerado, iniciado no fim do século XIX, surgiram vários métodos para determinação de idades absolutas. Segundo Alethéa et al. (2007), embora as técnicas de datação absoluta pareçam de análises simples, é dever do pesquisador, estudar de forma criteriosa o significado da idade fornecida por sua amostra. Sendo assim, nesta pesquisa iremos trabalhar com as datações absolutas por Luminescência Opticamente Estimulada (LOE, em inglês Optically Stimulated Luminescence $=$ OSL) e que de acordo com Lian e Roberts (2006) trata-se de uma propriedade física de materiais cristalinos ou vítreos, previamente submetidos a radiações ionizantes (raios cósmicos e isótopos radioativos), baseada na interação das radiações com a 
matéria, fundamentada no fato de que as idades dos materiais a serem datados podem ser calculadas pelas medidas das concentrações de indução por radiações ionizantes.

Outro método importante para identificação de compostos químicos é o uso da difração de raios X; bastante eficiente para o estudo da caracterização dos minerais e estudo dos cristais, tratase de um grande avanço no campo da cristalografia, bem como para geomorfologia. A difração de raios X é uma das ferramentas básicas para caracterização mineralógica. Assim, ao analisar argilominerais, a utilização da técnica de difração de raios $\mathrm{X}$ torna-se ainda mais indicada, pois uma análise química reportaria os elementos químicos presentes no material, mas não as formas como eles estão ligadas (NEVES, 1968; SANTOS, 1989).

Portanto, neste artigo o objetivo principal foi investigar, a textura, a mineralogia e a geocronologia de um murundum e sua relação concernentes com as características geomorfológicas, a qual exerce papel preponderante na qualidade destes ecossistemas.

\section{2. ÁREA DE ESTUDO}

A área de estudo (Figura 1) se localiza no Chapadão do Diamante, inserido no Parque Nacional da Serra da Canastra - MG, sob coordenadas geográficas $20^{\circ} 12^{`} 54,6^{\prime \prime}$ e $46^{\circ} 28^{\prime} 32^{\prime \prime}$, fuso 23, Datum WGs 84, a uma altitude entre $1.460 \mathrm{~m}$ e $1.470 \mathrm{~m}$, tratando-se de um campo de murunduns, fitofisionomia comum nesta área.

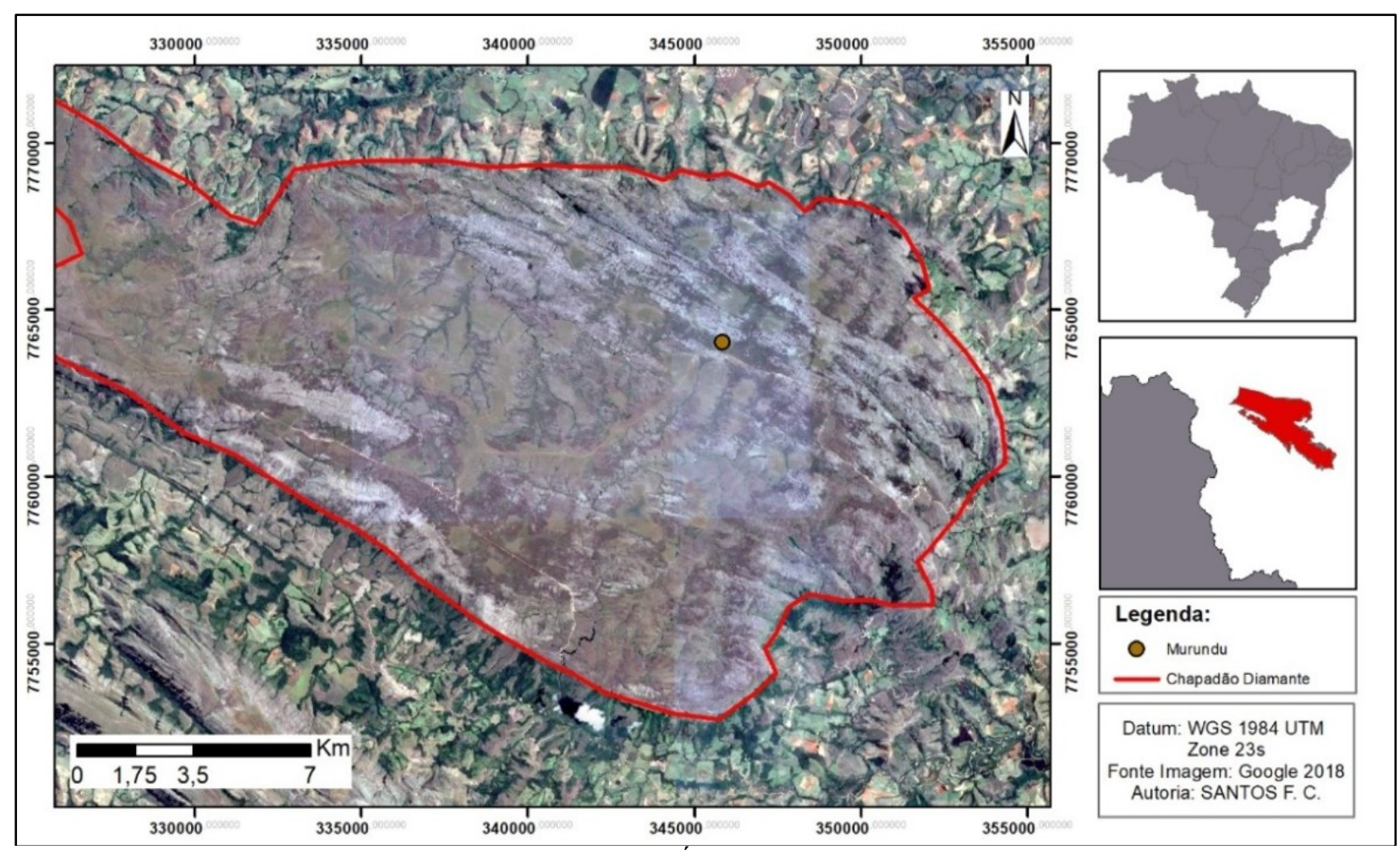

Figura 1- Área de estudo.

Fonte: Santos, 2019. 
De acordo Ab’Saber (1977) o Domínio Morfoclimático do Cerrado é caracterizado por chapadões cobertos por vegetação de cerrado e penetrado por floresta-galeria ao longo dos cursos d'água. A vegetação da área de estudo segundo a terminologia utilizada por Ribeiro e Walter (1998) perfaz a maior parte do Parque Nacional da Serra da Canastra e é coberta por formações campestres, subdivididas em formações savânicas do tipo cerrado sentido restrito, cerrado rupestre e formações campestres, onde ocorre campo limpo, campo-sujo e campo rupestre. (Figura 2).

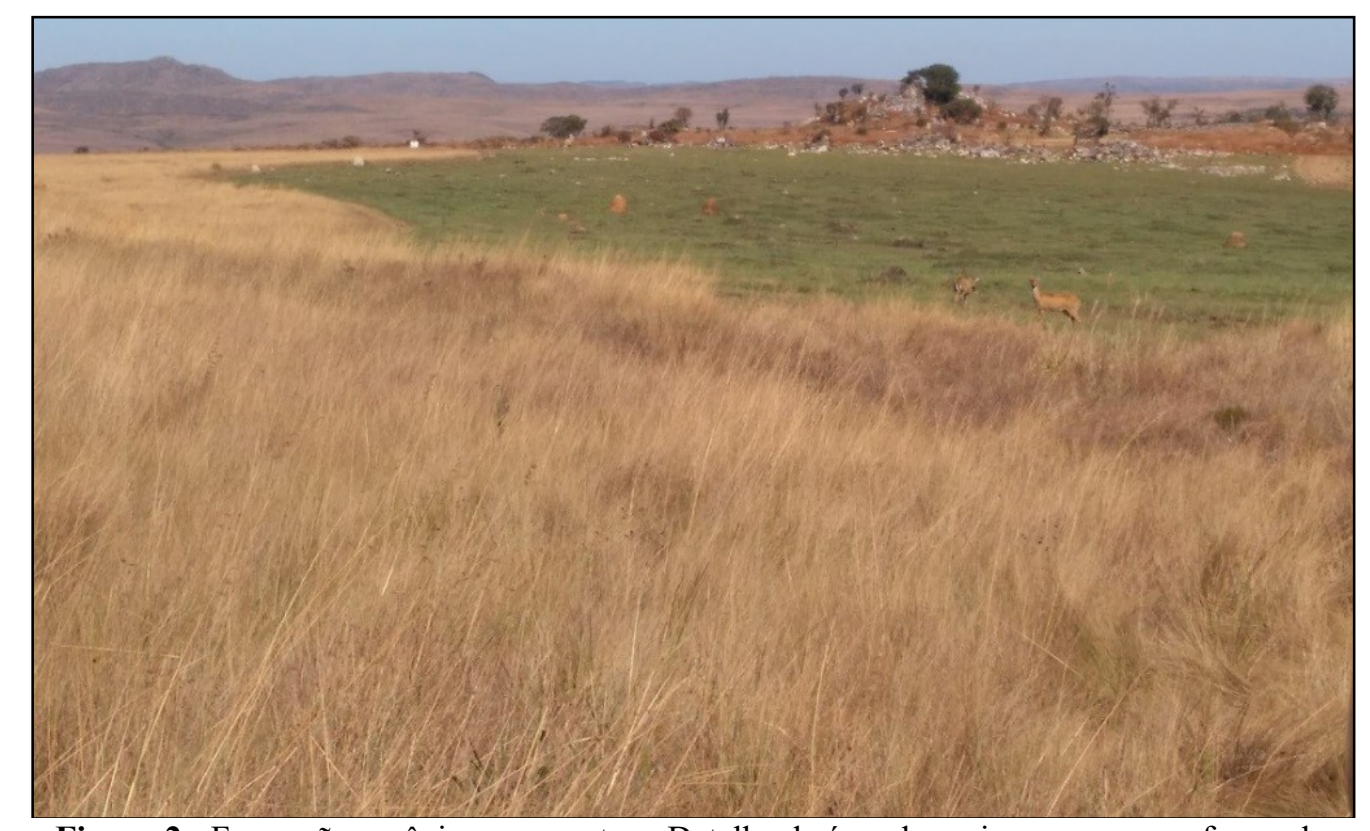

Figura 2 - Formação savânicas e rupestres. Detalhe da área de aceiro negro como forma de manejo para evitar a propagação de queimadas.

Fonte: Santos, 2018.

Segundo o Plano Diretor do Parque Nacional da Serra da Canastra, MMA (2005), o clima predominante do local de estudo é o tropical sazonal, de inverno seco. A temperatura média anual é de $23^{\circ} \mathrm{C}$, sendo que as médias mensais apresentam pequena estacionalidade. As estações, chuvosa e de entre chuvas, duram cerca de seis meses cada, devido ao deslocamento da área de influência das massas de ar que atuam sobre a região, sendo: Massa Equatorial Continental, Tropical Atlântica e a Massa de Ar Polar.

Estudos de Nazar (2018) e Souza e Rodrigues (2016), que contemplam a distribuição das classes de relevo da área, apontam, que cerca de $9 \%$ é destinada ao Relevo aplainado associado a interflúvios, $18 \%$ referem-se ao Relevo suavemente dissecado associado à colinas suaves, $22 \%$ ao Relevo dissecado associado à colinas onduladas e $17 \%$ ao Relevo fortemente dissecado associado a fundos de vales; enquanto que o Relevo em cristas alongadas associado a afloramentos quartzíticos ocupam $15 \%$ da área e o Relevo em escarpas estruturais percebem 9\%, as áreas de Relevo fortemente dissecado associado a morros atingem 10\% do total, encontrando também áreas de bioturbação (campo de murunduns) com área de 9,8\% (NAZAR; RODRIGUES, 2019a; 2019b). 


\section{MATERIAIS E MÉTODOS}

Para o desenvolvimento do presente trabalho foram feitas visitas à área de estudo, com o objetivo de coletar amostras do murundum, para avaliação das análises geoquímicas, textura, difratometria por raio-x (DRX) e geocronológicas de LOE.

Inicialmente foram realizadas tradagens para identificação de variações texturais. Após a identificação destas, um perfil que seccionou o murundum em sua metade foi realizado. A amostragem contou com coletas simples de solo no perfil do murundum, nas profundidades entre 0 a $110 \mathrm{~m}$ de profundidade. Posteriormente foram levadas para o Laboratório de Geomorfologia e Erosão dos Solos - LAGES-UFU- Campus Santa Mônica, onde a textura foi analisada pelo método da pipeta, utilizando solução de $\mathrm{NaOH}$ 0,1 mol L-1 como dispersante químico e agitação mecânica em aparato de alta rotação ( 15.000 rpm) por 15 min, seguindo Procedimento Operacional Padrão proposto por Santos e Rodrigues (2019).

Para coleta das amostras de LOE (Figura 3) foram utilizados tubos de PVC escuros, com $60 \mathrm{~cm}$ de comprimento e $6 \mathrm{~cm}$ de diâmetro com tampas bem ajustadas (MOREIRA,2017). As amostras para datação por LOE foram enviadas ao Laboratório Datação Comércio \& Prestação de Serviços LTDA e analisadas por meio do protocolo SAR (WINTLE; MURRAY, 2006).

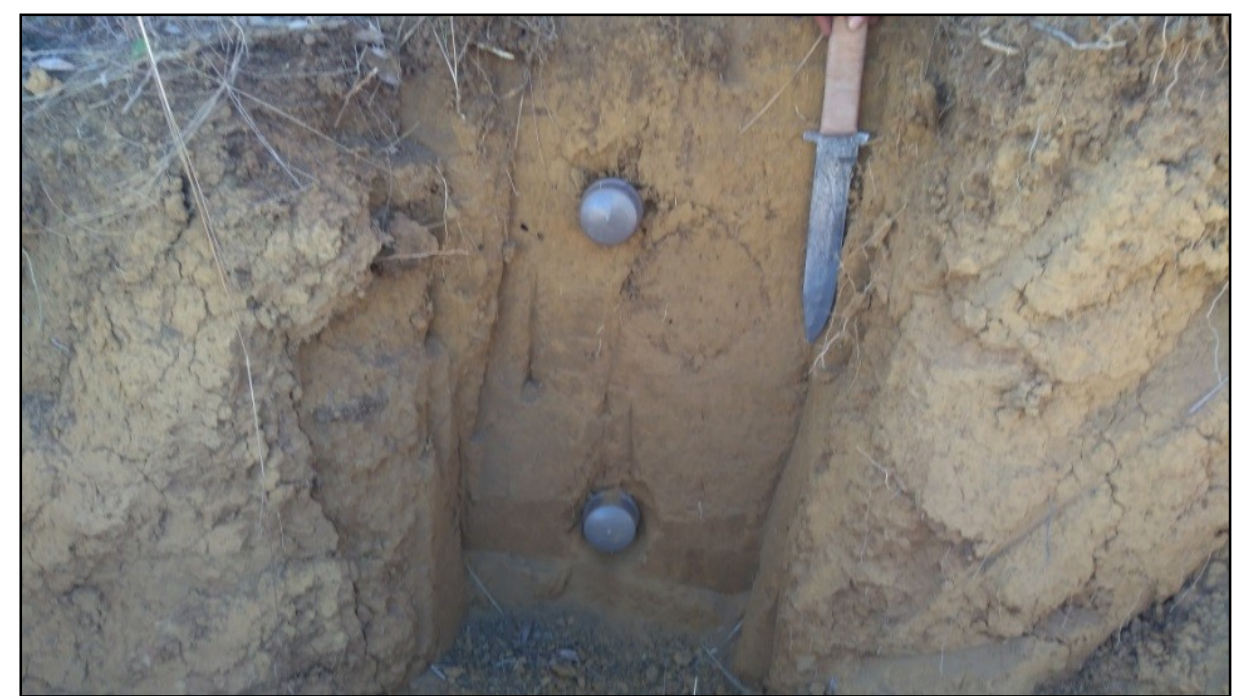

Figura 3 - Perfil do murundum aberto para coleta das amostras de LOE. Fonte: Santos, 2019.

As análises das amostras da fração argila, através de análise por DRX, cujo método baseiase na interação de ondas na frequência de raios X (geralmente entre 0,70 e 2,30 A) com os planos de repetição sistemática do retículo cristalino (NEVES, 1968), foram terceirizadas pelo Centro de Pesquisa Professor Manuel Teixeira da Costa-UFMG, onde foram trabalhadas conforme Metodologia Difratométrica de Argilominerais. 


\section{RESULTADOS E DISCUSSÃO}

Os resultados são apresentados em função da sequência das etapas estruturadoras deste estudo, para identificar as relações dinâmicas e de posicionamento dos componentes avaliados, através de reflexões sobre a interação material superficial-paisagem.

\subsection{Análise de DRX da fração de argila}

Através do ensaio de DRX obtivemos os dados necessários para geração do difratograma do mineral em estudo.

A maior presença demonstrada (Figura 4) de Gibbsita nas profundidades de 20-30 cm, 90$100 \mathrm{~cm}$ e $100-110 \mathrm{~cm}$ permite concluir que as condições para a formação do murundum, além da bioturbação, incluem uma elevada umidade, visto que é necessária uma relativa disponibilidade de água no sistema para mobilizar o ferro, além do fato de que a Goethita é formada pela hidratação da Hematita. Essa interpretação é reforçada pela presença comum da Gibbsita (Figura 4), à forma hidratada dos óxidos de alumínio nas amostras estudadas.

Assim, os campos de murunduns podem apresentar variações em razão do tipo e grau de encharcamento do solo, o qual pode estar relacionado à elevação do nível do lençol freático na estação chuvosa ou a um período de chuvas mais intenso (MARIMON; LIMA, 2001), mas frequentemente está ligado a áreas com drenagem deficiente (RENARD et al., 2012).

De acordo com o autor citado acima, para a formação das caulinitas, o mais importante do que a lixiviação de bases, é a redução da sílica $\left(\mathrm{SiO}_{2}\right)$ disponível no sistema. Assim, as porcentagens de caulinita nas amostras da Figura 4, está diretamente ligada ao teor de sílica $\left(\mathrm{SiO}_{2}\right)$ presente nas rochas quartizíticas da região (PLANO DE MANEJO DA SERRA DA CANASTRA, 2005). Onde portanto, observa-se uma intensa lixiviação, na sequência das respectivas profundidades demonstradas nos gráficos. Ou seja, pela ausência da sílica nas profundidades de 20$30 \mathrm{~cm}$ e $90-100 \mathrm{~cm}$ e com pico de $1,3 \%$ na profundidade de $100-110 \mathrm{~cm}$, favorecendo portanto, a formação da caulinita.

O aumento da presença dos compostos secundários Gibbsita, Caulinita, Clinocloro, Sílica e Muscovita na profundidade de 100-110cm, é explicado pela estabilidade desses minerais de acordo com ambiente de maior intemperismo, justificados, pela idade mais antiga observada nas análises geocronológica por LOE (Figura 6).

O intemperismo em quartzitos na região estudada é responsável pela dissolução do quartzo junto ao arranjo dos cristais (Figura 5). O processo geoquímico desagrega os quartzitos e quando, em junção com o intemperismo de subsuperfície, promove lixiviação da sílica, que por sua vez ocorre em mantos de alteração em estágios avançados, proporcionando a formação dos óxidos e 
hidróxidos de ferro e alumínio. Estes por sua vez, em quantidades suficientes, podem conduzir a processos de laterização.

A laterização e a intensa lixiviação favoreceram a formação de Goethita, Hematita e Gibbsita (Figura 4), elementos, que permitem sugerir que área está por muito tempo sobre a influência de um clima quente e úmido.
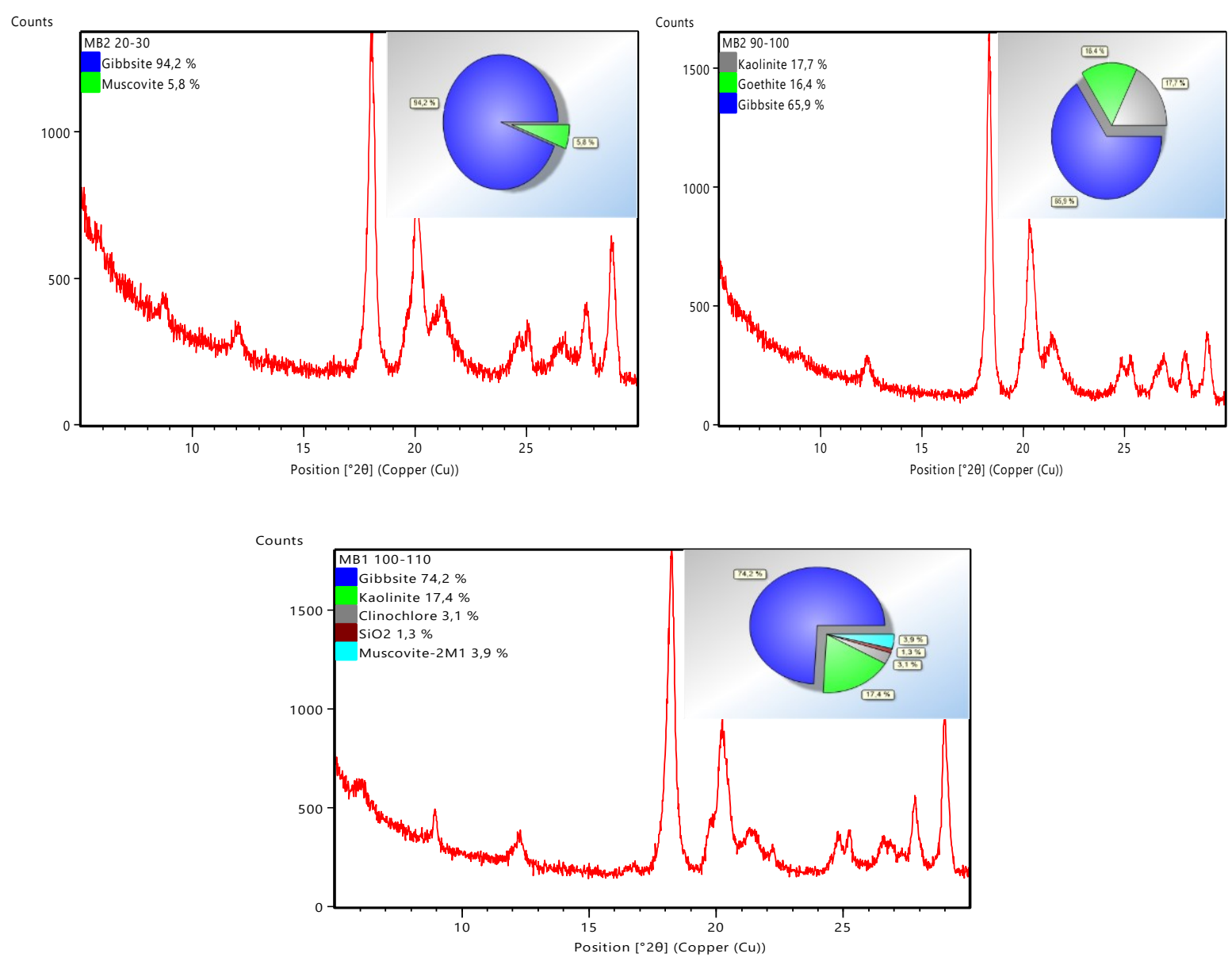

Figura 4 - Análises de DRX do murundum. Fonte: Autores, 2019.



Figura 5 - Dissolução em rocha quartzítica.

Fonte: Santos, 2019. 


\subsection{Luminescência Opticamente Estimulada (LOE)}

As hipóteses sobre o processo de formação dos campos de murunduns nesse estudo, são com base em fatores bióticos, como atividade de cupins, formigas, mamíferos e plantas, bem como em agentes abióticos, como vento e erosão hídrica (SARMIENTO; MONASTERIO, 1971; PAULINO et al., 2015).

No Brasil, estudos no Rio do Grande do Sul, encontraram três gêneros de térmitas colonizando campos de murunduns em zonas úmidas: Anaplotermes sp., Aparatermes sp. e Cortaritermes sp. (METHEWS, 1977; DIEHL et al., 2005), defendendo a hipótese biótica, explica que, primeiramente, uma espécie de térmita mais tolerante aos solos úmidos (Armitermes cerradoensis) instala-se e constrói um ninho pequeno na base de um tufo de capim; com o tempo, essa colônia morre e o cupinzeiro se desestrutura; posteriormente, o montículo de solo continua a ser aumentado durante o período chuvoso por outra espécie de cupim (Cornitermes snyderi), que se instala e constrói cupinzeiros maiores; em seguida, os montículos são desmontados e reconstruídos constantemente, formando montes de terra cada vez maiores e que passam a ser ocupados por espécies vegetais típicas da região.

O estudo abordado acima é sustentado nessa pesquisa por não excluir a atividade por bioturbação e depósito. Uma vez que análises de geocronologia por LOE (Tabela 1), demonstraram que na profundidade de $30 \mathrm{~cm}$ o resultado foi de $950 \pm 145$ anos enquanto que a profundidade de 60 cm foi de $2.500 \pm 390$ anos. Ou seja, materiais de idades recentes e mesmo constituintes químicos são encontrados mais próximos da superfície, corroborando com estudos de origem e evolução dos murunduns por fatores bióticos (METHEWS, 1977; OLIVEIRA FILHO, 1988).

Tabela 1 - Análise por Luminescência Oticamente Estimulada.

\begin{tabular}{cccc}
\hline Amostras & Dose anual(( $\boldsymbol{\mu G y / a n o )}$ & P(GY) & Idade (anos) \\
\hline C9- $60 \mathrm{~cm}$ & $2.210 \pm 200$ & 5,5 & $2.500 \pm 390$ \\
$\mathrm{C} 10-30 \mathrm{~cm}$ & $3.170 \pm 200$ & 3,0 & $950 \pm 145$ \\
\hline
\end{tabular}

Fonte: Laboratório Datação, 2018.

Segundo Resende et al. (2014), cada hipótese apresenta seus fatos e contradições. A origem biológica não explica o fato de a estrutura interna dos murunduns não apresentarem uma organização tipicamente biológica. Ao contrário, essa se assemelha, em vários aspectos, à estrutura dos Latossolos. A hipótese geomorfológica da erosão diferencial para os campos de murunduns também é incompatível com aspectos relacionados a esse microrrelevo e às situações em que ele ocorre (RESENDE et al., 2014).

O grande argumento contra a hipótese da gênese dos murunduns por erosão diferencial é o fato dela não explicar a existência de murunduns nas depressões fechadas, como na região de São 
Gotardo, MG, com microrrelevo mais desenvolvido do que sobre vertentes de vales tipo vereda (RESENDE et al., 2014).

\subsection{Textura}

A granulometria possibilita a identificação da dimensão das partículas que constituem o material analisado, proporcionando a compreensão dos agentes atuantes durante o transporte e deposição desse material.

A Figura 6, expõe uma larga predominância de partículas de granulometria fina, nas diferentes profundidades do murundum. A primeira explicação mais direta para tal fato, está relacionada ao tipo de quartzo da área fonte. No entanto, não se pode desconsiderar o fato de que estes materiais vêm sendo erodidos e intemperizados, tanto do ponto de vista químico, quanto físico, ao longo de uma larga escala de tempo. Ou seja, em condições favoráveis, os quartzos de diâmetro maiores acabam por se quebrar, formando diâmetros menores.

Também, foram encontradas nestes materiais, concreções ferruginosas, indicando uma ação cimentante dos óxidos de ferro sobre essas frações mais grosseiras. Figueiredo (1999) observou, nos solos da região de Gouveia, que os óxidos de ferro em frações muito pequenas podem aglutinar as argilas, podendo se comportar como pseudo-silte e mesmo areia fina, provocando um aumento da granulometria de argila para silte e areia fina, mas sem a formação de crosta laterítica.

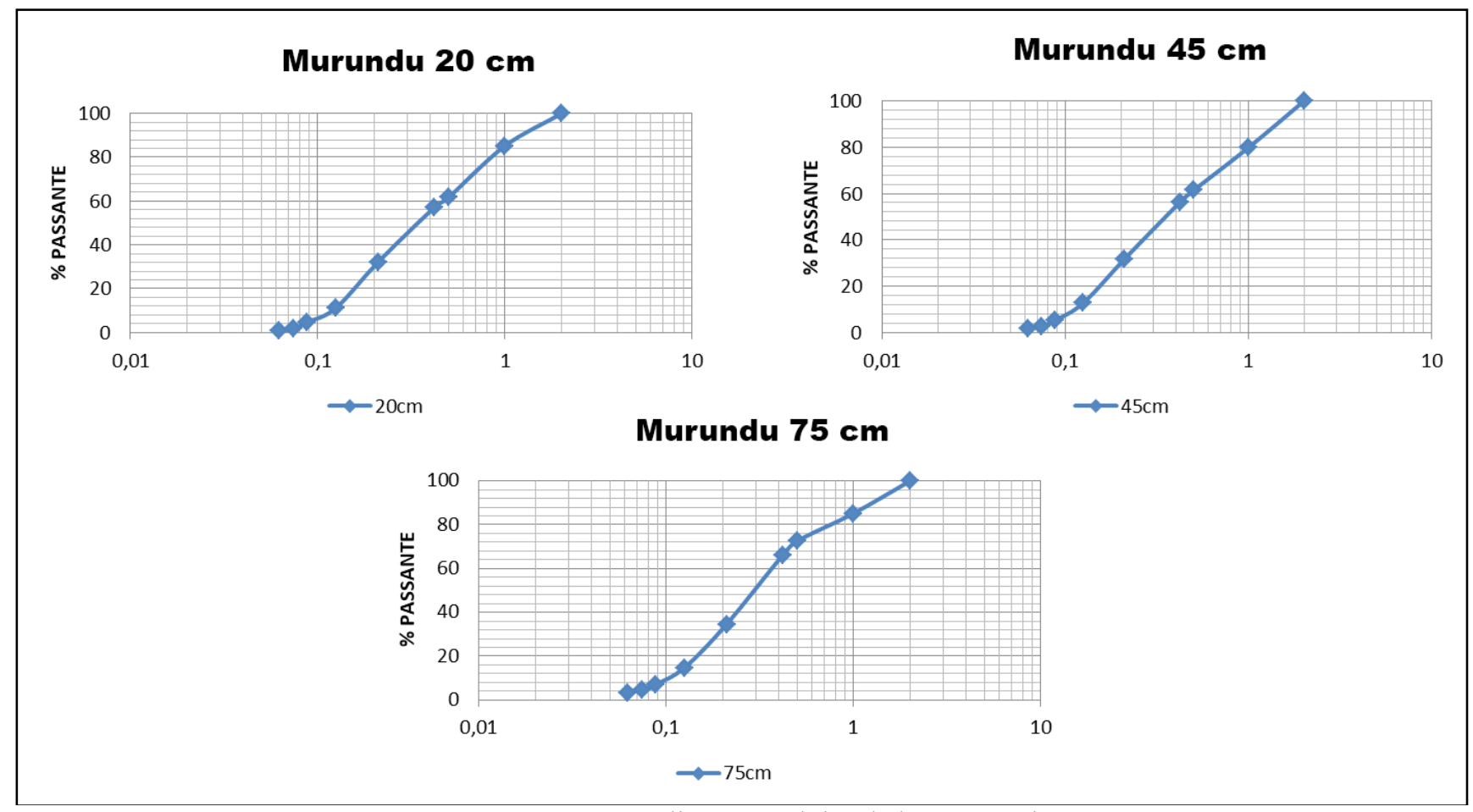

Figura 6 - Análise textural dos dados amostrais.

Fonte: Autores, 2019. 
A organização interna das camadas superiores dos murunduns tem relação estreita com o que se observa na superfície. No seu interior, são observadas estruturas granulares que representam metade da massa total do murundum. Essas estruturas residuais diminuem com a profundidade (se desfazendo com o tempo - antiguidade) e a partir da meia altura para baixo apresentam-se homogêneas, massivas, porosas e muito friáveis, à semelhança dos Latossolos das chapadas de características semelhantes desse estudo. Nódulos argilosos pequenos, mais endurecidos ou menos endurecidos são observados frequentemente (ROCHA, 2011; FUMIYA, 2017), (Figura 7).

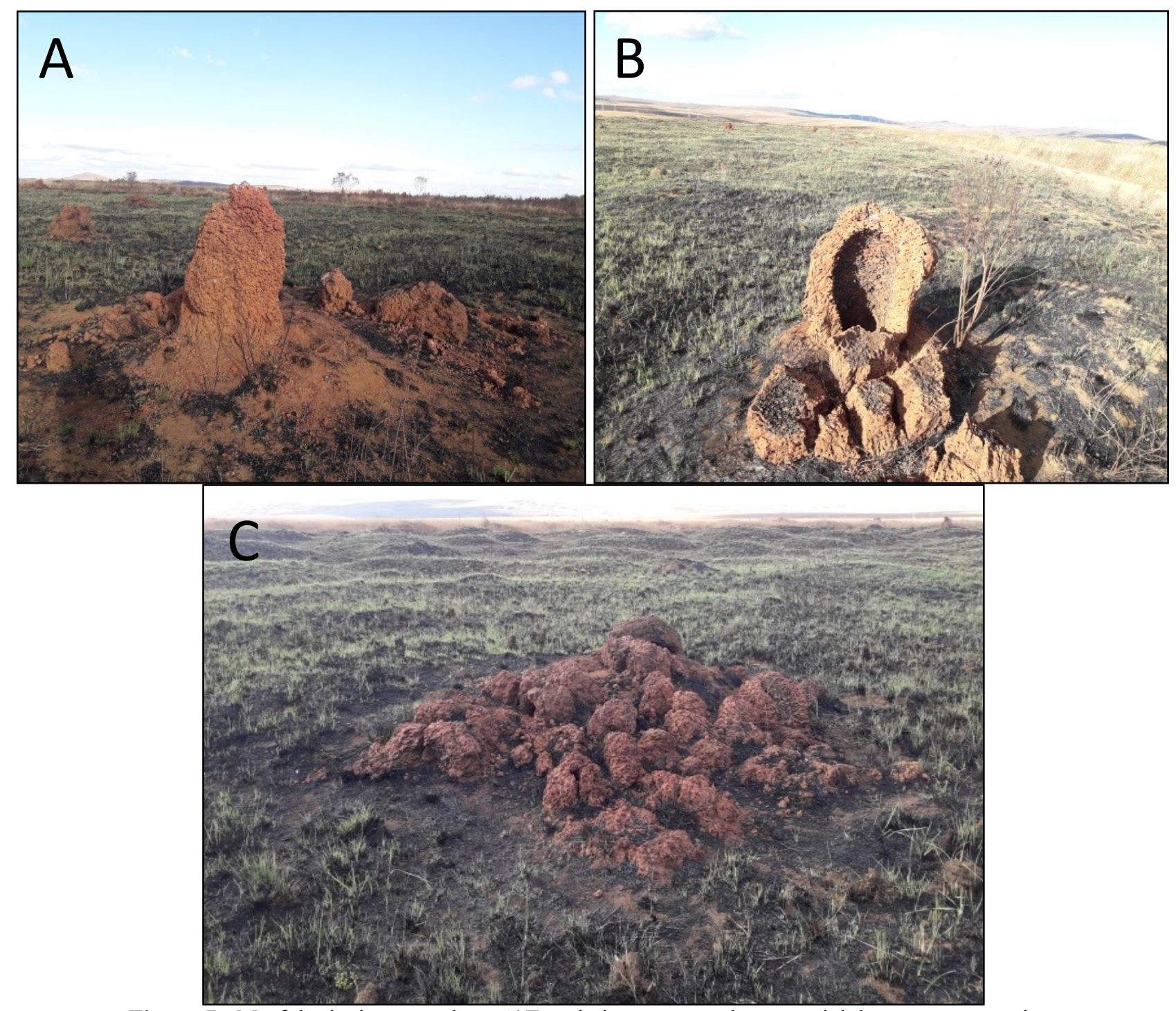

Figura 7 - Morfologia do murundum. A)Termiteiro recente sobre material decomposto anterior. B) Termiteiro em fase inicial de decomposição. C)Montículo em decomposição.

Fonte: Confessor, 2019.

A análise da morfologia em conjunto com a textura, corrobora com os estudos de Resende et al. (2014), sendo mais bem expressa nos murunduns mais elevados e, principalmente, naqueles amplos, porém já rebaixados (senescentes), onde a morfologia interna é compatível àquela dos solos à sua volta. 


\section{CONSIDERAÇÕES}

Diante das análises foi possível chegar a algumas reflexões em relação à dinâmica do murundum, enquanto objeto de estudo, incluindo as possibilidades de evolução dos materiais superficiais-paisagem que a região sugere.

A análise geoquímica, demonstra que a topografia e a posição da paisagem são relevantes, uma vez que geram variadas influências nas propriedades dos materiais superficiais, mesmo quando estes são fortemente intemperizados e possuem um grau elevado de homogeneidade.

A análise da textura dos materiais superficiais, mostrou que as frações granulométricas em materiais superficiais são atributos condicionados pela evolução do murundum, sendo sua variabilidade condicionada pela posição na paisagem, devido a processos erosionais ou deposicionais, associados ao fluxo de água.

A atividade por bioturbação é o principal condicionante da dinâmica do murundu.

O estudo da geocronologia, juntamente com a técnica de DRX demonstraram satisfatórios para elucidar a hipótese de bioturbação e depósito dos murunduns e ganham importância à medida que tenta caracterizar a sua espacialização, dinâmica e explicação das relações dos materiais superficiais com os campus de murunduns, uma vez que traz a tona as possibilidades da evolução do relevo.

\section{AGRADECIMENTOS}

Agradecimentos à Fundação de Amparo à Pesquisa do Estado de Minas Gerais (FAPEMIG) pelo projeto APQ CRA 0231/2016 e ao apoio do ICMBio Unidade São Roque de Minas.

\section{REFERÊNCIAS}

AB' SABER, A. N. Espaços ocupados pela expansão dos climas secos na América do Sul, por ocasião dos períodos glaciais quaternários. Paleoclimas, São Paulo, v. 3, p. 3-19, 1977.

ARAUJO NETO, M. D.; FURLEY, P. A.; HARIDASAN, M.; JOHNSON, C. E. The murunduns of the Cerrado region of central Brazil. J Trop Ecol., v. 2, p. 17-35, 1986.

CASTRO JÚNIOR, P. R. Dinâmica da água em campos de murunduns do Planalto dos Parecis. 2002. 193 f. Tese (Doutorado em Geografia) - Departamento de Geografia, Universidade de São Paulo, São Paulo, 2002.

DIEHL, E.; JUNQUEIRA, L.; BERTI-FILHO, E. Ant and termite mound coinhabitants in the wetlands of Santo Antonio da Patrulha, Rio Grande do Sul, Brazil. Braz. J. Biol., v. 65, n. 3, p. 431-437, 2005. 
EMPRESA BRASILEIRA DE PESQUISA AGROPECUÁRIA (Embrapa). Centro Nacional de Pesquisa de Solos. Manual de métodos de análise de solo. 2. ed. Rio de Janeiro: Embrapa CNPS, 1997. 212p.

FIGUEIREDO, M. A. Óxidos de ferro pedogênicos e sua influência na agregação de partículas de argila estudo de caso nos solos da região de Gouveia - Serra do Espinhaço Meridional MG. 95 p. Dissertação (Mestrado em Geografia) - Instituto de Geociências, Universidade Federal de Minas Gerais. Belo Horizonte, 1999.

FUMIYA, M. H.; SANTOS, L. J. C.; RIFFEL, S. B. Materiais ferruginosos e sua relação com a evolução do relevo no Noroeste do Paraná. In: SIMPÓSIO NACIONAL DE GEOMORFOLOGIA, 11., 2016, Maringá. Anais... Maringá: UGB, 2016. p. 1.

ICMBIO. 2005. Plano de Manejo do Parque Nacional da Serra da Canastra. Brasília. 2005. 250p.

MATHEWS, A. G. A. Studies on térmites from the Mato Grosso State, Brazil. Rio de Janeiro: Academia Brasileira de Ciências, 1977. 267p.

MARIMON, B. S.; LIMA, E .D. S. Caracterização fitofisionômica e levantamento florístico preliminar no pantanal dos rios Mortes-Araguaia, Cocalinho, Mato Grosso, Brasil. Acta Bot Bras., v. 15, p. 213-229, 2001.

MOREIRA, V. B. Geocronologia em ambientes de veredas e campos de murundus na chapada Uberlândia-Uberaba: subsídios à evolução da paisagem. 2017. 129 f. . Dissertação (Mestrado em Geografia) - Instituto de Geociências, Universidade Estadual de Campinas, Campinas, 2017.

NAZAR, T. I. S. M. O Chapadão do Diamante na Serra da Canastra/MG, Brasil: caracterização geomorfológica e análise integrada do meio físico a partir de dados multifontes. 2018. 270 f. Tese (Doutorado em Geografia) - Instituto de Geografia, Universidade Federal de Uberlândia, Uberlândia, 2018.

NAZAR, T. I. S. M.; RODRIGUES, S. C. Relevo do Chapadão do Diamante, Serra da Canastra/MG, Brasil: compartimentação e análise a partir dos aspectos geomorfométricos. Revista Brasileira de Geomorfologia, São Paulo, v. 20, n. 1, p. 69-88, 2019a. http://dx.doi.org/10.20502/rbg.v20i1.1300

NAZAR, T. I. S. M.; RODRIGUES, S. C. Mapeamento e análise de Geocoberturas no Chapadão do Diamante - MG - Brasil. Mercator, v. 18, n. 05, p. 1-17, $2019 \mathrm{~b}$. http://dx.doi.org/10.4215/rm2019.e18010

NEVES, L. E. Estudo prático de argilas por difratometria de raios X - Boletim Técnico da Petrobrás, v. 11, n. 1, p. 123-135, 1968.

OLIVEIRA FILHO A. T. Furley P. Monchão, cocuruto, murundu. Ci. Hoje, v. 11, p. 11-30, 1990.

RESENDE, M.; CURI, N.; REZENDE, S.; CORRÊA, G.; KER, J. Pedologia: Base para distinção de ambientes. 6. ed. Lavras: Universidade Federal de Lavras; 2014. 378p.

RENARD, D.; BIRK, J.; GLASER, B.; IRIARTE, J.; GRISARD, G.; KARL, J.; MCKEY, D. Origin of mound-field landscapes: A multi-proxy approach combining contemporary vegetation, carbon stable isotopes and phytoliths. Plant Soil. v. 351, p. 337-357, 2012. 
RIBEIRO, J. F.; WALTER, B. M. T. Fitofitofisionomia do Bioma Cerrado. In: SANO, S. M.; ALMEIDA, S. P. (Eds.) Cerrado: ambiente e flora. Brasília: Embrapa, 1998. p.89-166.

RIBEIRO J. F, ALMEIDA S, SANO S. Cerrado: Ecologia e flora. 1. ed. Brasília: Embrapa; 2008. 406p.

ROCHA, L. C.; AUGUSTIN, H. R. R.; CRUZ, L. O. M. O Papel Geomorfológico das Lateritas no Espinhaço Meridional. In: SIMPÓSIO NACIONAL DE GEOMORFOLOGIA, 7., 2008, Belo Horizonte. Anais... Belo Horizonte: UGB, 2008. P. 5-15.

SAllun, A. E. M.; SUGUIO, K.; TATUMI, S. H. ; YEE, M. ; SANTOS, J. ; BARRETO, A. M. F. Datação absoluta de depósitos quaternários brasileiros por luminescência. São Paulo: Revista Brasileira de Geociências, v. 37, n. 2, p. 401-412, 2007.

SARMIENTO, G. MONASTERIO, M. Ecología de las sabanas de America Tropical. Analisis macroecológico de los llanos de Calabozo, Venezuela. Cuad Geogr. v. 4, p. 1-26, 1971.

SANTOS, F. C.; RODRIGUES, S. C. Procedimento Operacional Padrão (POP) - Laboratório de Geomorfologia e Erosão de Solos. 30p. Uberlândia, 2019. DOI:10.13140/RG.2.2.11998.59202

SANTOS, P. S. Ciência e tecnologia de argilas. 2. ed. São Paulo: Edgard Blücher Ltda, 1989. $234 p$.

SOUZA, D. A.; RODRIGUES, S. C. Aspectos Morfoestruturais da Serra da Canastra e entorno (MG). Revista do Departamento de Geografia - USP, São Paulo, v. 27, p. 47-66, 2014. https://doi.org/10.11606/rdg.v27i0.472

WINTLE, A. G.; MURRAY, A. S. A review of quartz optically stimulated luminescence characteristics and their relevance in single-aliquot regeneration dating protocols. Rations Measurements, v. 41, p. 369-391, . 2006. 